\title{
Wing and body size polymorphism in populations of the stonefly Arcynopteryx dichroa McL. (Plecoptera: Perlodidae) in the Ural Mountains, Russia
}

\author{
Olga A. Loskutova ${ }^{1}$ \& Lidia A. Zhiltzova ${ }^{2}$ \\ 1 Institute of Biology, Komi Scientific Center, Ural Branch of the Russian Academy of Sciences, Kommunisticheskaya 28, Syktyvkar 167982, Russia \\ 2 Zoological Institute of the Russian Academy of Sciences, Universitetskaja naberežnaja 1, St. Petersburg 199034, Russia
}

\section{Keywords}

Wing length; short-winged population;

Urals; mountain lakes; latitude; isolation.

\section{Correspondence}

Olga A. Loskutova, Institute of Biology, Komi Scientific Center, Ural Branch of the Russian Academy of Sciences, Kommunisticheskaya 28, RU-167982 Syktyvkar, Russia.

E-mail: loskutova@ib.komisc.ru

\begin{abstract}
Specimens from five Arcynopteryx dichroa (McL.) populations were examined to study wing length and body size at different latitudes and altitudes. In northern Europe, female $A$. dichroa are usually long winged, while males are short winged. During the past 20 years, only two short-winged populations have been found, in a nameless lake, herein called Lake Ozernoe, and in Bolshaya Lagorta Lake, in Russia's Ural Mountains. In the isolated population of Ozernoe Lake ( $850 \mathrm{~m}$ a.s.l.), both sexes were micropterous. In Bolshaya Lagorta Lake (380 m a.s.l.), females were brachypterous. However, at a higher altitude (560 and $760 \mathrm{~m}$ a.s.l.), a population was found with macropterous females. Specimens of both short-winged populations had smaller body length than long-winged populations. Our findings give limited support to the idea that stonefly wings are reduced with altitude and latitude and more support to the supposition that small wing size is associated with population isolation resulting from lengthy geological isolation.
\end{abstract}

To access the supplementary material for this article, please see the supplementary files under Article Tools, online.
Wing polymorphism commonly occurs in many terrestrial and aquatic insects. The morphology of the wings in aquatic insects has significant variability (Harrison 1980) and is well expressed in a number of stonefly genera and species. Degree of wing development often varies even within the same species. Four forms of wing-length polymorphism are known in adult stoneflies: macropterism (long winged), brachypterism (short winged), micropterism (vestigial winged) and apterism (wingless) (Costello 1988). Flightless species are particularly common on islands, at high altitudes, in the Arctic and perhaps more generally among insects in cold climates (Harrison 1980).

There are a number of studies of reduced wing size in stoneflies (e.g., Hynes 1941; Brinck 1949; Lillehammer 1976; Costello 1988; Malmqvist 2000). Some species display genetically determined short wingedness (Donald \& Patriquin 1983). A number of species of Capniidae
(Lillehammer 1976) and several species of Brachyptera and Leuctra are short winged. Several European Leuctra and Capnioneura and Siberian Baikaloperla and Allocapniella (Zwick 1980) are frequently characterized by complete apterism. Some other changes in imago morphology are correlated with short wingedness, such as lack of ocelli, reduction of thoracic sterna, strongly developed legs and sclerotization of the upper surface of the abdomen (which also occurs in wingless Leuctra females and capniids) (Zwick 1980; Lee \& Baumann 2011). Local populations of short-winged specimens are known to exist in isolated places for a number of species such as Amphinemura sulcicollis (Steph.) in northern England and Nemoura cinerea Retz., $N$. dubitans Mort. and N. erratica Claass. in Scandinavia (Illies 1955). Stark \& Baumann (2005) discovered micropterous populations of the perlodid Megarcys subtruncata Hanson in Quinn River, OR. An isolated population of 
Illiesonemoura ornata (McL.) with short-winged males and females was found by LAZ in a small brook in the Darvaz range in the Badakhshan Mountains (west Pamir). At other sites (West Tian-Shan, Gissaro-Darvaz) male and female I. ornata have wings of normal length (Zhiltzova 2003). A tendency to short wingedness has often been found among local populations and at high altitudes (Lillehammer 1976).

Reduced wing size is normally found in males in a number of species: Diura bicaudata L., Isoperla difformis (Klap.), Dinocras cephalotes (Curt.), Perlodes dispar (Ramb.), P. microcephala Pict., Perla bipunctata Pict., Capnia bifrons Newm. and C. vidua Klap (Zwick 1980; Lillehammer 1985, 1988; Costello 1988). The males of this species are mostly micropterous. Although this diminishes the males' possibility of finding winged females, the males compensate for the small size of their wings by being particularly active (Zwick 1980). In some populations of Arcynopteryx dichroa, wings are reduced to different degrees but sometimes only a part of a population has short wings; in other populations, the whole population is short winged (Lillehammer 1985). In Lake Teletskoye (Altay Mountains), the males of $A$. dichroa are mainly short winged but there are also some long-winged specimens. Of 341 males examined, only six appeared to be long winged (Zapekina-Dulkejt 1955).

There is dependence between wing length and the length of the other parts of the stonefly's body. Zwick (1980) showed a direct dependence between wing size and body size in Perlodes dispar (Ramb.) and that short winged, small males emerge after bigger, long-winged individuals. In addition, variation in wing length is often accompanied by changes in the characters of the genitalia (Lillehammer 1974).

Arcynopteryx dichroa McL. survived Pleistocene glaciations in the central European periglacial region and postglacially retreated to higher altitudes and latitudes (Theissinger et al. 2009). Currently A. dichroa has a circumpolar distribution and in continental Europe it occurs at high altitudes (Lillehammer 1988). Size, body colour and wing length of $A$. dichroa vary considerably in different areas. In Scandinavia, the males are always micropterous, and the females have normally developed wings (Brinck 1949; Illies 1955). In the Pyrenees, $A$. dichroa display three combinations of wing lengths: (1) both sexes have normal wings; (2) males are micropterous and females brachypterous; and (3) males and females are micropterous (Despax 1951).

In the European part of Russia, female $A$. dichroa are always long winged or slightly short winged, while males are usually short winged (Loskutova 2006). The goals of this work were to compare long- and short-winged populations of $A$. dichroa and to analyse what environmental factors - latitude, altitude, isolation and riparian vegetation-are associated with short wingedness in stoneflies in the Polar and Pre-Polar Urals.

\section{Materials and methods}

Located in the Ozernaya River basin in the Pre-Polar Urals, a nameless lake herein called Ozernoe Lake $(850 \mathrm{~m}$ a.s.l., $64^{\circ} 50^{\prime} \mathrm{N}, 59^{\circ} 14^{\prime} \mathrm{E}$ ) is surrounded by high mountains with year-round snow (Fig. 1, Supplementary Fig. S1). It has an area of about $0.15 \mathrm{~km}^{2}$ and lacks an outflowing stream. Between mountain ranges in the Polar Urals, Bolshaya Lagorta Lake ( $380 \mathrm{~m}$ a.s.l., $66^{\circ} 31^{\prime} \mathrm{N}, 63^{\circ} 3 \mathrm{l}^{\prime} \mathrm{E}$ ) is about $0.48 \mathrm{~km}^{2}$ in area (Fig. 1, Supplementary Fig. S2). This lake is not isolated: from it flows the stream Levaya Lagorta. Both lakes are characterized by large boulder substrata without overgrowth. Stonefly specimens were collected during the adult emergence period of shortwinged stoneflies, in Ozernoe Lake in August 2007 and in Bolshaya Lagorta Lake in August 2010, when the water temperature was $7.0-9.0^{\circ} \mathrm{C}$.

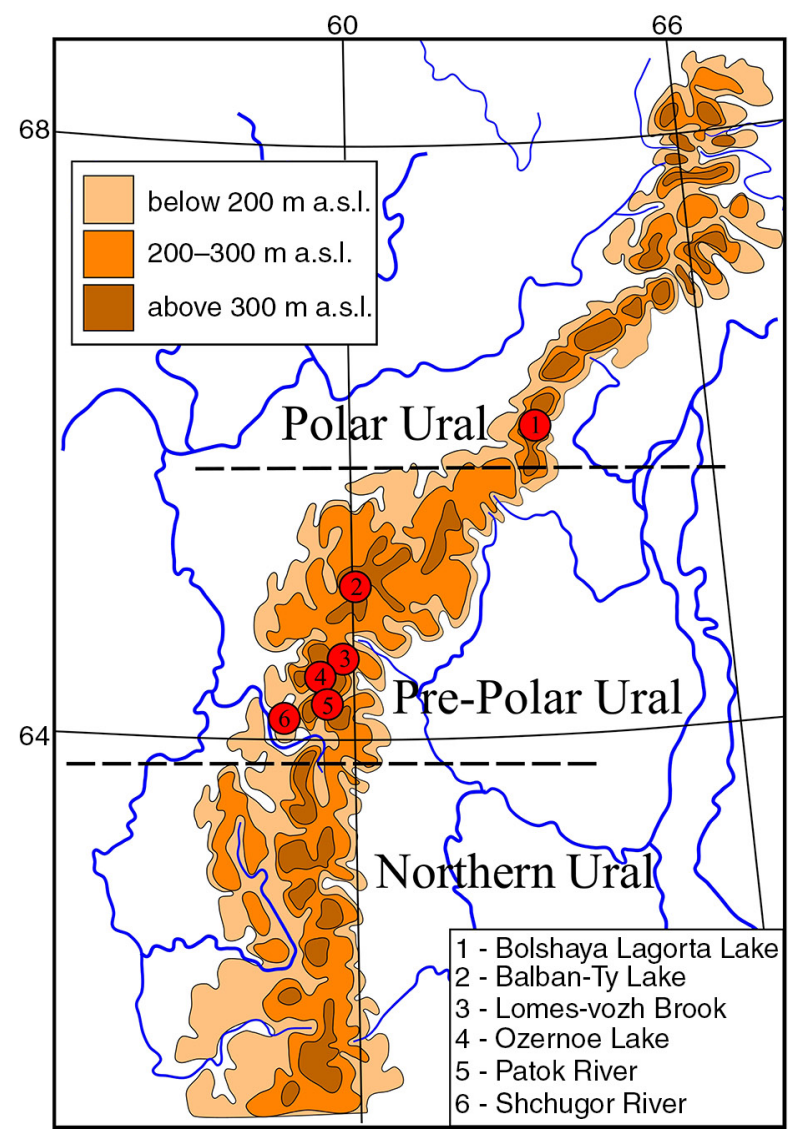

Fig. 1 Study sites in the Ural Mountains, Russia. 
For comparative purposes, insects were collected from other streams and lakes in the Pre-Polar Urals: the small Patok River $\left(64^{\circ} 40^{\prime} \mathrm{N}, 59^{\circ} 40^{\prime} \mathrm{E}\right)$ and Lomes-vozh Brook $\left(64^{\circ} 56^{\prime} \mathrm{N}, 59^{\circ} 51^{\prime} \mathrm{E}\right)$, which are about 11 to $13 \mathrm{~km}$ in length, Shchugor River $\left(64^{\circ} 21^{\prime} \mathrm{N}, 58^{\circ} 28^{\prime} \mathrm{E} ; 300 \mathrm{~km}\right.$ in length) and Balban-Ty Lake $\left(65^{\circ} 12^{\prime} \mathrm{N}, 60^{\circ} 15^{\prime} \mathrm{E}\right.$; area $0.9 \mathrm{~km}^{2}$ ). Along the north-western shore of Balban-Ty Lake is a shaft of the lateral moraine. From the Balban-Ty Lake, a river flows into a broad longitudinal valley.

Adult Plecoptera were sampled by searching under stones along lake shores and riversides, or by sweeping the vegetation growing along rivers, and were placed in $96 \%$ ethanol. In the laboratory, body length (from the front of the head to the tip of the abdomen) and fore- and hindwing length of each specimen were measured using a light microscope $(0.01 \mathrm{~mm}$ accuracy). Statistics 6.0 for Windows was used for data analysis. Differences between body length in long-winged and short-winged specimens were tested using the Kolmogorov-Smirnov nonparametric test (Statistica 6). Significance levels were $P<0.05$ and $P<0.001$.

We characterized wing development using the terms macropterous for long wings, brachypterous for moderately short wings and micropterous for very short wings. Both brachypterous and micropterous stoneflies are described here as "short winged."

\section{Results}

In Ozernoe Lake, OAL found an isolated population of Arcynopteryx dichroa with micropterous males and females. Another short-winged population of A. dichroa was found on the shores and in the outlets of Bolshaya Lagorta Lake, where the females were mainly brachypterous and males were micropterous. In Ozernoe Lake, female wings were twice as long as those of males. The average length of the fore- and hindwings of females in all long-winged populations (Table 1) was calculated at 14.50 and $13.30 \mathrm{~mm}$, respectively, whereas these measurements in the females of the short-winged populations at Ozernoe Lake were only 3.97 and $3.38 \mathrm{~mm}$, respectively. The females from Bolshaya Lagorta Lake had longer fore- and hindwings, at 5.98 and $5.64 \mathrm{~mm}$, respectively. Average male fore- and hindwing length was less variable compared with females: maximum 3.82 and $3.20 \mathrm{~mm}$, minimum 1.90 and 1.50, respectively. Environmental parameters, number of specimens and measurements of $A$. dichroa from different populations are presented in Table 1.

Venation of the brachypterous females from Bolshaya Lagorta Lake was strongly reduced (Fig. 2b). All veins were truncated, cross-veins in the costal area were

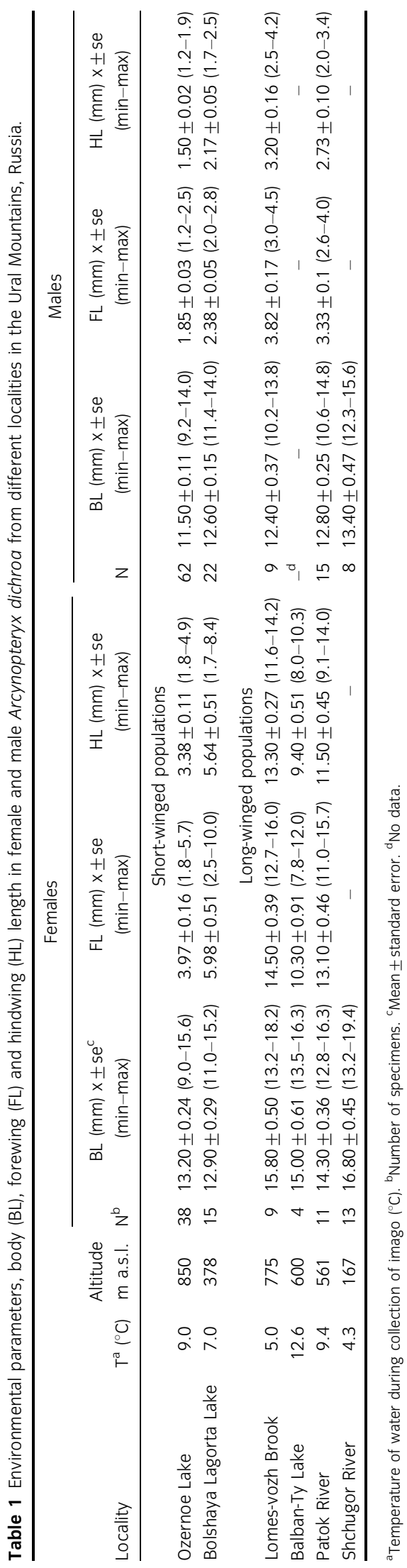




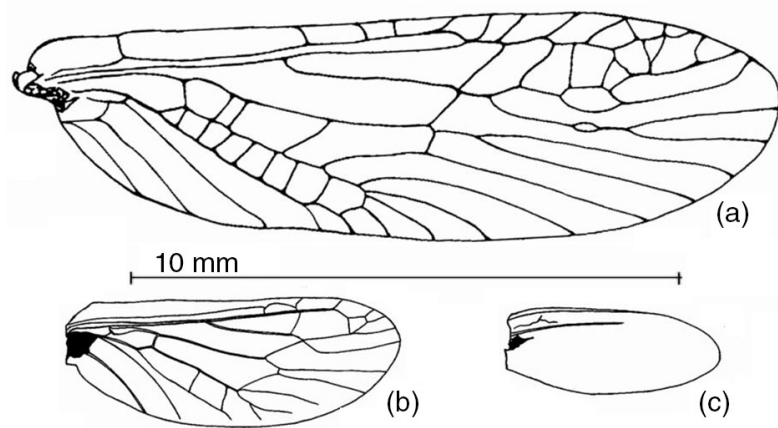

Fig. 2 The venation of forewings of different populations of Arcynopteryx dichroa in the Ural Mountains, Russia: (a) macropterous (from Lillehammer 1988), (b) brachypterous and (c) micropterous.

completely absent, there were few cross-veins between $\mathrm{R}$ and Rs branches, cross-veins were absent between $M$ and $\mathrm{Cu}$, there were two instead of seven veins between $\mathrm{Cu}_{1}$ and $\mathrm{Cu}_{2}$ and the number of anal veins was reduced from three to two. Micropterous wing veins (Fig. 2c) were almost completely absent: only the subcostal veins and radius veins remained. A strongly sclerotized spot was present at the base of the wings.

Adult stoneflies also varied widely in body size (Table 1). Females from Bolshaya Lagorta Lake were smaller than those from other sampled sites. The average body length of short-winged females ranged from 12.90 to $13.20 \mathrm{~mm}$ and long-winged females ranged from 14.30 to $16.8 \mathrm{~mm}$. Average male body length in the short-winged populations varied from 11.5 to $12.6 \mathrm{~mm}$. Specimens of both short-winged populations had smaller body sizes than long-winged populations; this was significant at the $P<0.001$ level. Average female body length in both short-winged populations was $13.10 \pm 0.19 \mathrm{~mm}$ and among all long-winged females was $15.60 \pm 0.28 \mathrm{~mm}$. Average male body length in the short-winged populations was $11.70 \pm 0.11 \mathrm{~mm}$ and in long-winged populations was $12.80 \pm 0.20 \mathrm{~mm}$.

Body length of specimens from long-winged populations tended to diminish with increasing latitude (females: $R=-0.17, P<0.05$; males: $R=-0.32, P<0.05$; Fig. 3$)$. Short-winged specimens had shorter average body length than long-winged specimens at all latitudes, with the exception of males from Bolshaya Lagorta Lake.

Short-winged populations were found at different altitudes. Bolshaya Lagorta Lake is $378 \mathrm{~m}$ a.s.l. and Ozernoe Lake is $850 \mathrm{~m}$ a.s.l., but all the females from these two lakes were short winged (Fig. 4). Females and males from a sampled site (Shchugor River) at a lower altitude (167 m a.s.l.) had longer bodies, on average, than those of other long-winged populations (Fig. 5). Body length of long-winged specimens was weakly
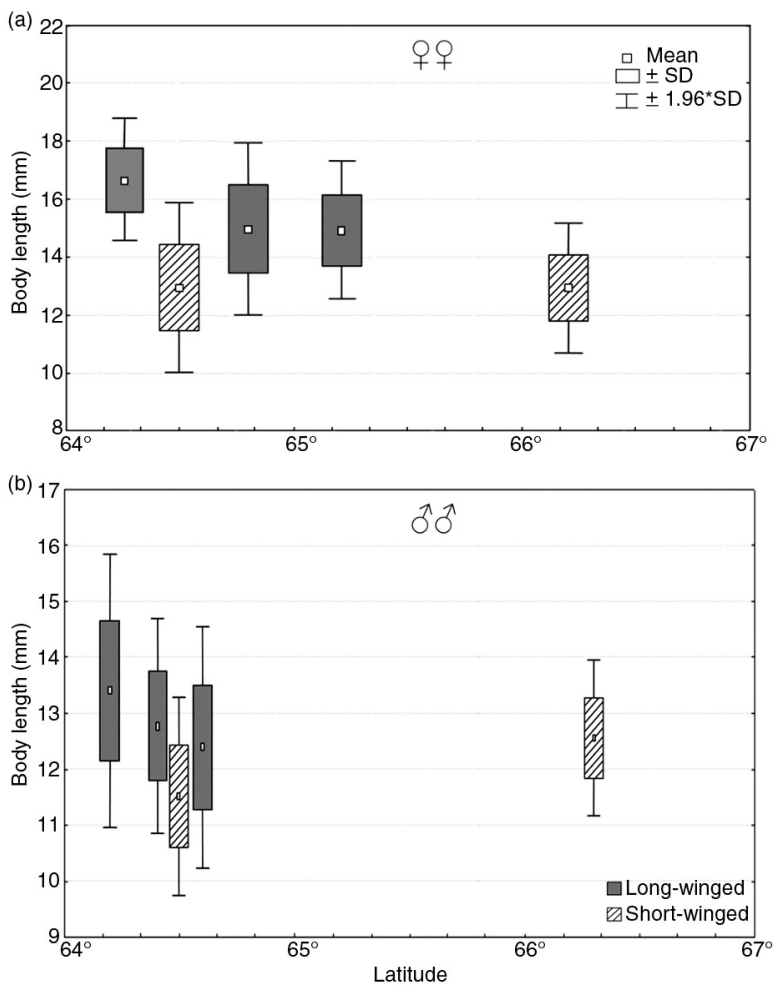

Fig. 3 Box and whisker plots of variability of body length among (a) females and (b) males of Arcynopteryx dichroa and latitude in the Ural Mountains, Russia.

negatively correlated with altitude (females: $R=-0.37$, males: $R=-0.34$ ); only the correlation between female body length and altitude was strongly significant $(P<0.05)$. Short-winged females had shorter bodies than long-winged females from different sites independent of altitude (Fig. 5).

\section{Discussion}

Insects show a wide range of adaptations to the extreme environmental conditions of the Arctic, where most aquatic habitats are frozen for many months. According to Danks (2004), insect adaptations to the Arctic include activity at low temperatures, selection of warm microhabitats and prolonged life cycles with diapause.

Short-winged local populations of stoneflies have mainly been found in cold climates (Lillehammer 1976). The life cycle of short-winged Arcynopteryx dichroa in Ural lakes differs from the long-winged population. Long-winged $A$. dichroa emerge earlier (in early June), have brief synchronized reproduction and hatching of eggs take place in July. The juvenile larvae grow during the summer and winter and emerge in June the following year (Loskutova 2007). We observed short-winged 


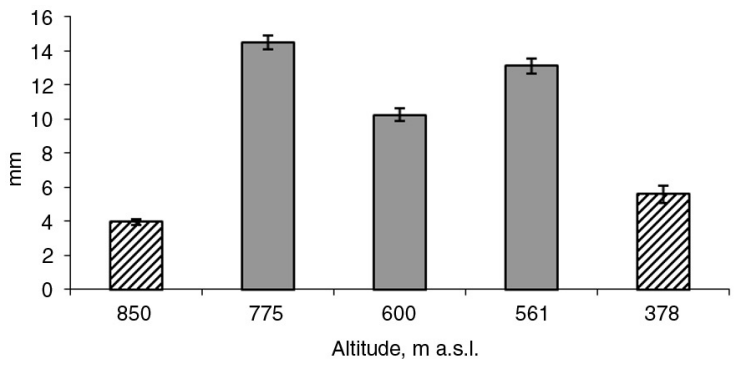

Fig. 4 Forewing length of Arcynopteryx dichroa females versus altitude in the Ural Mountains, Russia.

populations emerging in August. Eggs of short-winged populations are deposited in autumn and apparently have a diapause during the winter.

Reduction in body length is often accompanied by a reduction in wing length (Lillehammer 1985). In this study, we found that specimens of short-winged populations from Ural lakes had smaller bodies than those of all long-winged populations $(P<0.001)$. Similar dependence was found for the stonefly Perlodes dispar (Zwick 1980). Reduction of body length may be associated with the limited food in these small ultraoligotrophic lakes. Short-winged, small-bodied specimens are flightless throughout their lives, requiring low amounts of energy resources to find sexual partners. This is consistent with the argument that flight capacity may be reduced to allocate more energy to egg production and fecundity (Roff 1990).
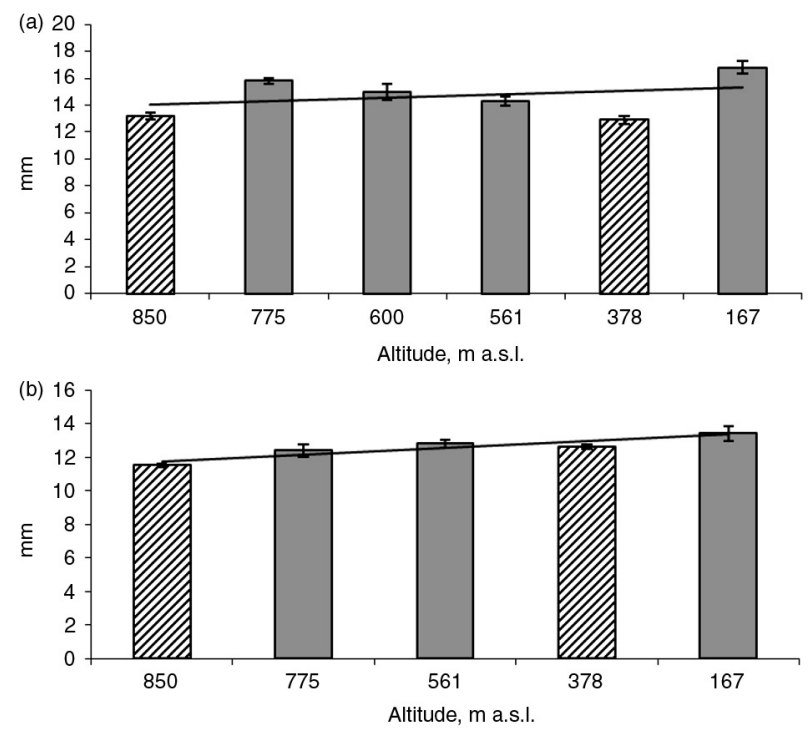

Fig. 5 The relationship among (a) females and (b) males between body length of Arcynopteryx dichroa at different altitudes in the Ural Mountains, Russia.
Hynes (1941) noted that short wingedness increases northward. Our investigation did not show a strong correlation between short wingedness and latitude, which may be because of the relatively small range of latitudes represented by our study sites. Lillehammer (1976) stated that short-winged local populations were mainly found at high altitudes. There is evidence that short wingedness in the stonefly Amphinemura standfussi Ris was more abundant in the mountain areas than in the lowland localities of Sweden (Brinck 1949). However, we found short-winged populations at different altitudes (380 and $850 \mathrm{~m}$ a.s.l.), which suggests that wing length may not be determined only by altitude.

Slater (1977) suggested that the proportion of flightless insect species reflects the stability of an area in evolutionary time. Harrison (1980) observed that when habitat patches are isolated, the number of flightless forms among insects increases over time. Stark \& Baumann (2005) explained short wingedness in the stonefly Megarcys subtruncata by its probable more pronounced isolation by mountainous topography. In the sites we investigated, Bolshaya Lagorta and Ozernoe lakes are both located between mountains ridges, but Bolshaya Lagorta Lake is not isolated: a river flows out of this lake. Although females had short wings in both lakes, this was less pronounced in Bolshaya Lagorta Lake compared with Ozernoe Lake. Females in Bolshaya Lagorta Lake were mainly brachypterous; only two female specimens had very short wings (micropterous). Females in Ozernoye Lake were micropterous. Females from Ozernoye and Bolshaya Lagorta lakes, surrounded by high mountains, were short winged, while females from the lake BalbanTy, surrounded by the lesser barrier of a low moraine, were long winged. Our findings support the supposition that short wingedness is associated with populations that have inhabited an isolated mountain area for a long period.

Vinçon \& Ravizza (2000) described the eight brachypterous or apterous Leuctra species of stonefly, proposing that a strong reduction or complete lack of wings may be linked to the particular ecological preferences of these crenophilous insects: they live in springs and brooklets with are often rich in hydrophilic vegetation in which adults take refuge and can move more easily with short wings. These insects have developed other features adapting them for moving in dense vegetation (Vinçon \& Ravizza 2000). However, we found short-winged populations on rocks without vegetation. Long-winged specimens of $A$. dichroa, in contrast, were found on trees along the rivers and brooks, with deciduous or mixed forests in the catchment (e.g., the Shchugor and Patok rivers and the Lomes-vozh Brook). 
Why some stoneflies have short wings is not yet well understood. Our research shows that wing and body size polymorphism in stonefly populations in the Ural Mountains is not clearly associated with altitude or latitude, riparian vegetation, but seems to depend more on the isolation of the population. Molecular genetic studies are proving useful in identifying the location of refugia from which insects colonized Europe after the last Ice Age and how isolated relict populations diverged genetically (Hewitt 1999). Genetic analysis of different populations of $A$. dichroa (Theissinger et al. 2009; Theissinger et al. 2013), especially short-winged ones, may shed light on the genetic component of wing morph determination.

\section{Acknowledgements}

This research was supported by the Basic Research Project of the Ural Branch of the Russian Academy of Sciences in 2015-17 no. 15-15-4-36. We are grateful to two anonymous reviewers for their comments and suggestions.

\section{References}

Brinck P. 1949. Studies on Swedish stoneflies (Plecoptera). Opuscula Entomologica Supplementum 11. Lund: Entomological Society.

Costello M.J. 1988. Preliminary observations on wing-length polymorphism in stoneflies (Plecoptera: Insecta) in Ireland. The Irish Naturalists Journal 22, 474-478.

Danks H.V. 2004. Seasonal adaptations in Arctic insects. Integrative and Comparative Biology 44, 85-94.

Despax R. 1951. Plécopterès. Fauna de France 55. (Plecoptera. Fauna of France 55.) Paris: Paul Lechevalier.

Donald D.B. \& Patriquin D.E. 1983. The wing length of lentic Capniidae (Plecoptera) and its relationship to elevation and Wisconsin glaciation. The Canadian Entomologist 115, 921-926.

Harrison R.G. 1980. Dispersal polymorphism in insects. Annual Review of Ecology and Systematics 11, 95-118.

Hewitt G.M. 1999. Post-glacial re-colonization of European biota. Biological Journal of the Linnean Society 68, 87-112.

Hynes H.B.N. 1941. The taxonomy and ecology of the nymphs of British Plecoptera with notes on the adults and eggs. Transactions of the Royal Entomological Society of London 91, 459-557.

Illies J. 1955. Steinfliegen oder Plecoptera. Tierwelt Deutschland und angrenzenden Meeresteile Teil 43. (Stoneflies of the order Plecoptera. Fauna of Germany and adjacent marine areas. Part 43.) Jena: G. Fischer.

Lee J.J. \& Baumann R.W. 2011. Mesocapnia aptera (Plecoptera: Capniidae) a new wingless winter stonefly from northern California, USA. Illiesia 7, 192-196.
Lillehammer A. 1974. Norwegian stoneflies. Analyses of the variations in morphological and structural characters used in taxonomy. Norsk Entomologiski Tidsskrift 21, 59-107.

Lillehammer A. 1976. Norwegian stoneflies V. Variation in morphological characters compared to differences in ecological factors. Norwegian Journal of Entomology 23, 161-172.

Lillehammer A. 1985. Studies of shortwingedness in stoneflies (Plecoptera). Fauna Norvegica Series B 32, 58-61.

Lillehammer A. 1988. Stoneflies (Plecoptera) of Fennoscandia and Denmark. Fauna Entomologica Scandinavica 21. Copenhagen: E.J. Brill/Scandinavian Science Press.

Loskutova O.A. 2006. Fauna evropejskogo severo-vostoka Rossii. Vesnjanki (Plecoptera). T. IX. (Fauna of the European north-east of Russia. Stoneflies [Plecoptera] Vol. 9). Saint Petersburg: Nauka.

Loskutova O.A. 2007. Life cycles, growth and production of stonefly populations. In F.R. Hauer et al. (eds.): International advances in the ecology, zoogeography and systematics of mayflies and stoneflies. Pp. 61-78. Berkeley, CA: University of California Press.

Malmqvist B. 2000. How does length relate to distribution patterns of stoneflies (Plecoptera) and mayflies (Ephemeroptera)? Biological Conservation 93, 271-276.

Roff D.A. 1990. The evolution of flightlessness in insects. Ecological Monographs 60, 389-421.

Slater J.A. 1977. The incidence and evolutionary significance of wing polymorphism in lygaeid bugs with particular reference to those of South Africa. Biotropica 9, 217-229.

Stark B.P. \& Baumann R.W. 2005. A micropterous, crenondwelling population of Megarcys subtruncata Hanson (Plecoptera: Perlodidae). Western North American Naturalist 65, $131-132$.

Theissinger K., Balint M., Feldheim K.A., Haase P., Johannesen J., Laube J. \& Pauls S.U. 2013. Glacial survival and postglacial recolonization of on Arctic-alpine freshwater insects (Arcynopteryx dichroa, Plecoptera, Perlodidae) in Europe. Journal of Biogeography 40, 236-248.

Theissinger K., Feldheim K.A., Seitz A. \& Pauls S.U. 2009. Isolation and characterization of 11 polymorphic trinucleotide microsatellite markers in the stonefly Arcynopteryx compacta (Plecoptera: Perlodidae). Molecular Ecology Resources 9, 357-359.

Vinçon G. \& Ravizza C. 2000. New micropterous microendemic Leuctra species and subspecies from the Spanish Cordillera Cantabrica (Plecoptera Leuctridae). Bollettino della Società Entomologica Italiana 132, 195-203.

Zapekina-Dulkejt J.I. 1955. Plecoptera severo-vostocnogo Altaja. (Plecoptera of north-east Altai.) Zametki po Faune $i$ Flore Sibiri 18, 30-38.

Zilcova [Zhiltzova] L.A. 2003. Fauna Rossii i sopredelnyh stran. Nasekomye, Vesnjanki. Insecta, Plecoptera 1(1). (Fauna of Russia and neighbouring countries. Insecta, Plecoptera 1[1].) Saint Petersburg: Nauka.

Zwick P. 1980. Plecoptera (Steinfliegen). Handbuch der Zoologie 26. (Plecoptera [Stoneflies]. Zoology handbook 26.) Berlin: Walter de Gruyter. 